\title{
Borderline Personality Disorder, Exposure to Interpersonal Trauma, and Psychiatric Comorbidity in Urban Primary Care Patients
}

\author{
Maren Westphal, Mark Olfson, Margarita Bravova, Marc J. Gameroff, Raz Gross, \\ Priya Wickramaratne, Daniel J. Pilowsky, Richard Neugebauer, Steven Shea, \\ Rafael Lantigua, Myrna Weissman, and Yuval Neria
}

\begin{abstract}
Objective: Few data are available on interpersonal trauma as a risk factor for borderline personality disorder (BPD) and its psychiatric comorbidity in ethnic minority primary care populations. This study aimed to examine the relation between trauma exposure and BPD in low-income, predominantly Hispanic primary care patients. Method: Logistic regression was used to analyze data from structured clinical interviews and self-report measures $(n=474)$. BPD was assessed with the McLean screening scale. Trauma exposure was assessed with the Life Events Checklist (LEC); posttraumatic stress disorder (PTSD) was assessed with the Lifetime Composite International Diagnostic Interview, other psychiatric disorders with the SCID-I, and functional impairment with items from the Sheehan Disability Scale and Social Adjustment Scale Self-Report (SAS-SR). Results: Of the $57(14 \%)$ patients screening positive for BPD, $83 \%$ reported a history of interpersonally traumatic events such as sexual and physical assault or abuse. While interpersonal trauma experienced during adulthood was as strongly associated with BPD as interpersonal trauma experienced during childhood, non-
\end{abstract}

\footnotetext{
Maren Westphal, Ph.D., is affiliated with Department of Psychology at Pace University in Pleasantville, New York, and with the Department of Psychiatry at Columbia University in New York City. Mark Olfson, M.D., M.P.H., Marc J. Gameroff, Ph.D., and Priya Wickramaratne, Ph.D., are affiliated with the Department of Psychiatry at Columbia and the Division of Epidemiology at the New York State Psychiatric Institute in New York City. Margarita Bravova, M.S., is with the Division of Clinical Therapeutics at the New York State Psychiatric Institute in New York City. Raz Gross, M.D., with the Department of Psychiatry at Columbia and the Department of Epidemiology at the Mailman School of Public Health at Columbia. Daniel J. Pilowsky, M.D., and Myrna Weissman, Ph.D., are with the departments of Psychiatry and Epidemiology at Columbia, and the Division of Epidemiology at the New York State Psychiatric Institute. Richard Neugebauer, Ph.D., is with the divisions of Epidemiology and General Medicine at the New York State Psychiatric Institute. Steven Shea, M.D., is with the departments of Epidemiology and Medicine at Columbia. Rafael Lantigua, M.D., is with the Division of General Medicine at the New York State Psychiatric Institute and the Department of Medicine at Columbia. Yuval Neria, Ph.D., is with the departments of Psychiatry and Epidemiology at Columbia and the divisions of Epidemiology and Clinical Therapeutics at the New York State Psychiatric Institute.

Funding was received from the NIMH: 1RO1-MHO72833 (Dr. Neria); NARSAD (Dr. Neria); Eli Lilly \& Company (Dr. Weissman); and the New York State Psychiatric Institute (Drs. Neria, Wickramaratne, Olfson, Gameroff, and Weissman).

Address correspondence to Maren Westphal, Ph.D., Pace University, Department of Psychology, 861 Bedford Rd., Pleasantville, NY 10570. E-mail: mwestphal@pace.edu
} 
interpersonal trauma was associated with BPD only if it had occurred during childhood. The majority (91\%) of patients screening positive for BPD met criteria for at least one current DSM-IV Axis I diagnosis and exhibited significant levels of functional impairment. Conclusion: Increased awareness of BPD in minority patients attending primary care clinics, high rates of exposure to interpersonal trauma, and elevated risk for psychiatric comorbidity in this population may enhance physicians' understanding, treatment, and referral of BPD patients.

Borderline personality disorder (BPD) is a severe and chronic psychiatric disorder that is marked by pervasive instability across multiple domains involving affect, behavior, interpersonal relationships, selfimage, and cognitive functions (Crowell, Beauchaine, \& Linehan, 2009; Paris, 2005; Zanarini, Frankenburg, Hennen, Reich, \& Silk, 2005; Zlotnick et al., 2003). A number of studies investigating the contribution of interpersonal trauma in the etiology of BPD have singled out childhood sexual abuse (CSA) as a major psychological risk factor for BPD (Lubit, Rovine, DeFrancisci, \& Eth, 2003; Modestin, Furrer, \& Malti, 2005; Van den Bosch, Verheul, Langeland, \& Van den Brink, 2003). However, while adverse childhood experiences tend to be highly prevalent among patients with BPD, CSA is neither a necessary nor sufficient cause for development of BPD (Fossati, Madeddu, \& Maffei, 1999; Zanarini, 2000).

Understanding the relative contribution of interpersonal versus other types of trauma to the clinical presentation of individuals with $\mathrm{BPD}$ is important given that early interpersonal trauma is associated with increased re-victimization (Widom, Czaja, \& Paris, 2009). Economically disadvantaged ethnic minority women are at particularly high risk for domestic violence and other adult interpersonal trauma (Bryant-Davis, Chung, \& Tillman, 2009) and are therefore an important population to target in mental health screening initiatives and research on associations between interpersonal trauma and BPD. Yet relatively few studies of BPD have examined the relationship between trauma exposure and BPD in primary care settings, where low-income patients typi- cally receive most of their mental health care (Gresenz, Sturm, \& Tang, 2001; Olfson et al., 1996). As a result, ethnic minorities have been underrepresented in BPD research, which has tended to focus on community samples (Bornovalova, Hicks, Iacono, \& McGue, 2009; Grant et al., 2008; Korfine \& Hooley, 2009; Samuels et al., 2002; Torgersen, Kringlen, \& Cramer, 2001) or clinical populations (Gunderson et al., 2006; Korzekwa, Dell, Links, Thabane, \& Webb, 2008; Pascual et al., 2008; Widiger \& Weissman, 1991).

Prevalence rates of BPD range from $1-2 \%$ in the general population (Samuels et al., 2002; Torgersen et al., 2001), $8-27 \%$ in psychiatric outpatient settings, and $15-51 \%$ among psychiatric inpatients (Gunderson et al., 2006; Korzekwa et al., 2008; Pascual et al., 2008; Widiger \& Weissman, 1991). The few studies that have examined BPD among primary care patients (Gross et al., 2002; Hueston, Werth, \& Mainous, 1999; Sansone \& Sansone, 2003; Sansone, Whitecar, Meier, \& Murry, 2001) have reported prevalence rates $(6.4-26 \%)$ that are substantially higher than those observed in the general population.

Regarding prevalence among ethnic minorities, a study using data from the Collaborative Longitudinal Personality Disorders Study (CLPS) on treatment-seeking individuals found disproportionately higher rates of BPD in Hispanic compared to Caucasian and African American samples (Chavira et al., 2003), though an earlier study found no group differences (Castaneda \& Franco, 1985). While research on cultural differences in BDP symptom presentation and diagnostic efficiency is scarce, a num- 
ber of studies that included different ethnic groups have found similar diagnostic efficiency and reliability of DSM-IV BPD criteria in Hispanic samples compared to White samples (e.g., Chavira et al., 2003; Grilo, Becker, Anez, \& McGlashan, 2004; Grilo et al., 2001). Similarly, a recent study that used a relatively large, ethnically diverse sample of young adults found that the same four factors in BPD symptomatology emerged when analyzing different ethnic groups (Selby $\&$ Joiner, 2008).

One of the differences that may account for higher rates of BDP among Hispanics is exposure to trauma. Hispanics tend to have greater levels of trauma exposure (Kulka et al., 1990; Perilla, Norris, \& Lavizzo, 2002) than other ethnic groups, including severe interpersonal trauma such as sexual assault (Nnamdi, Joseph, \& Madhur, 2008). To our knowledge, no previous study has compared the relative contribution of interpersonal versus non-interpersonal trauma to BPD and associated clinical and functional impairment among predominantly Spanishspeaking, low-income minority primary care patients.

The present study aimed to bridge this gap in knowledge by examining differences in trauma exposure, clinical status, and functional impairment between patients with and without BPD in a well-characterized sample of urban, low-income primary care patients attending a large medical clinic in New York City. We addressed three questions: (1) Do primary care patients with BPD have higher rates of interpersonal trauma involving sex$\mathrm{ual} /$ physical assault and abuse than patients without BPD? (2) Is BPD more strongly associated with interpersonal trauma experienced during childhood than with interpersonal trauma experienced during adulthood? and (3) How does the functional and psychiatric status of patients with BPD compare with that of patients without BPD when controlling for interpersonal trauma exposure and relevant demographic risk factors?

\section{METHOD}

The study was conducted at a group practice of the Division of General Medicine, Columbia University Medical Center, in New York City that serves approximately 20,000 patients each year with more than 80,000 annual visits. The institutional review boards of Columbia University Medical Center and the New York State Psychiatric Institute approved the study protocol.

\section{Participants}

Most of the participants were female, and the mean age $(S D)$ at baseline was 51.8 (10.8) years. A majority were members of ethnic minority groups, poor, had an immigrant ancestry, and were not currently married; more than half had completed at least 8 years of education (Table 1).

\section{Procedure}

The sample was comprised of primary care patients assessed face-to-face in two waves of data collection: Wave 1, between December 2001 and January 2003, and Wave 2, between January 2004 and May 2007. As described elsewhere (Neria et al., 2008, 2010, 2013; Weissman et al., 2010), eligible patients were between 18 and 70 years old, had made at least one previous visit to the practice, could speak and understand English or Spanish, were waiting for face-to-face contact with a physician, and were capable of completing the survey. Consecutive prospective subjects were approached to determine eligibility on the basis of the position of the seat they freely selected in the waiting room of the practice. Of the 1,117 patients who met eligibility criteria, 991 (88.7\%) consented to participate in the baseline study interview. The interview lasted an average of 90 minutes. Of these, $716(72.2 \%)$ con- 
TABLE 1. Demographic Characteristics and Borderline Personality Disorder Screening Status Among Adult Primary Care Patients $(n=474)$

\begin{tabular}{|c|c|c|c|c|c|c|}
\hline \multirow[b]{3}{*}{ Variable } & \multicolumn{4}{|c|}{$\begin{array}{c}\text { Borderline Personality Disorder Screening } \\
\text { Status a }\end{array}$} & \multirow[b]{3}{*}{$\chi^{2}$} & \multirow[b]{3}{*}{$p$} \\
\hline & \multicolumn{2}{|c|}{$\mathrm{BPD}+(n=57)$} & \multicolumn{2}{|c|}{ BPD- $(n=417)$} & & \\
\hline & $N$ & $\%$ & $N$ & $\%$ & & \\
\hline Age & & & & & 0.19 & .662 \\
\hline $18-54(n=206)$ & 27 & 50.9 & 179 & 47.7 & & \\
\hline $55-70(n=222)$ & 26 & 49.1 & 196 & 52.3 & & \\
\hline Gender & & & & & 0.29 & .589 \\
\hline Male $(n=122)$ & 13 & 22.8 & 109 & 26.1 & & \\
\hline Female $(n=352)$ & 44 & 77.2 & 308 & 73.9 & & \\
\hline Ethnicity & & & & & 4.96 & .026 \\
\hline Hispanic $(n=402)$ & 54 & 94.7 & 348 & 83.5 & & \\
\hline Non-Hispanic $(n=72)$ & 3 & 5.3 & 69 & 16.5 & & \\
\hline Marital status & & & & & 0.12 & .726 \\
\hline Married/co-habiting $(n=151)$ & 17 & 29.8 & 134 & 32.1 & & \\
\hline Separated/divorced/widowed/never married $(n=323)$ & 40 & 70.2 & 283 & 67.9 & & \\
\hline Education & & & & & 0.05 & .829 \\
\hline High school graduate $(n=263)$ & 31 & 54.4 & 232 & 55.9 & & \\
\hline Not high school graduate $(n=209)$ & 26 & 45.6 & 183 & 44.1 & & \\
\hline Annual Household Income & & & & & 0.27 & .603 \\
\hline$<\$ 12,000(n=335)$ & 38 & 69.1 & 297 & 72.4 & & \\
\hline$>\$ 12,000(n=130)$ & 17 & 30.9 & 113 & 27.6 & & \\
\hline Gainfully employed & & & & & 0.07 & .792 \\
\hline No $(n=315)$ & 37 & 64.9 & 278 & 66.7 & & \\
\hline Yes $(n=159)$ & 20 & 35.1 & 139 & 33.3 & & \\
\hline
\end{tabular}

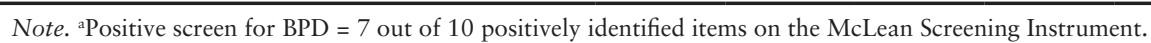

sented to be re-contacted for a follow-up interview. Consenters and non-consenters did not differ significantly in demographic characteristics or rates of mental or general medical disorders (Neria et al., 2006). At follow-up, these 716 patients were mailed an invitation for a face-to-face interview in English or Spanish, per participant preference, at Columbia University Medical Center. We offered participants a small monetary compensation to cover their transportation expenses and potential loss of work hours. Non-responders were mailed a second invitation, then telephoned, and if non-responsive were assigned a home visit. Of the 716 eligible for follow-up, 139 (19.4\%) could not be located and were lost to follow-up despite consistent and systematic efforts to contact them. No significant differences were found in baseline demographic characteristics and mental health status between the contacted sample $(n=577)$ and patients lost to follow-up $(n=$ 139). Of the 577 patients, 65 refused to participate in the follow-up assessment. The remaining 512, who were either re-interviewed $(n=474)$, found to be deceased $(n=27)$, or unavailable due to illness or institutionalization $(n=11)$, represent $72 \%$ of the followup sample of 716 , and $52 \%$ of the baseline sample of 991 . The 474 subjects who were re-interviewed comprise the analytic sample for this study. Of them, 99 patients $(20.9 \%)$ chose to be interviewed in English and 375 patients $(79.1 \%)$ chose to be interviewed in Spanish. 


\section{Measures}

Sociodemographic Characteristics and Trauma Exposure. Gender, age, marital status, ethnicity, education, annual household income, employment status, and country of birth were assessed at baseline. Trauma exposure was measured with a modified version of the Life Events Checklist (LEC; Gray, Litz, Hsu, \& Lombardo, 2004), a 17-item scale assessing exposure to various types of common traumatic events. Trauma exposure was determined by a positive report ("happened to me") of at least one of the following events: natural disaster, fire or explosion, serious accident, exposure to toxic substances, physical assault, assault with weapon, sexual assault, other unwanted sexual experience, combat exposure, captivity, life-threatening illness or injury of self or close family member, a sudden or violent death, a sudden unexpected death of someone close, a serious injury, harm, or death caused to somebody else, transportation accident, or any other very stressful event or exposure, excluding bereavement, chronic illness, business loss, marital or family conflict, or reaction to a book, movie, or television program. We also assessed the patient's age at first experience of each trauma.

Because traumatic events involving interpersonal aggression or violation are particularly likely to result in PTSD (Breslau et al., 1998; Kessler, Sonnega, Bromet, Hughes, \& Nelson, 1995) and have been associated with higher rates of BPD (Battle et al., 2004; Ogata et al., 1990; Yen et al., 2002; Zanarini, 2000; Zanarini et al., 1997), we created a summary "interpersonal trauma" variable composed of the following four items: "physical assault (for example, being attacked, hit, slapped, kicked, beaten up)," "assault with weapon (for example, being shot, stabbed, threatened with a knife, gun, bomb)," "sexual assault (rape, attempted rape, made to perform any type of sexual act through force or threat of harm)," and "other unwanted or uncomfortable sexual experience.”
To capture other types of non-assaultive traumatic events, we created a summary "non-assault trauma" variable including all other types of the 17 events listed in the LEC. In order to differentiate between trauma experienced in childhood versus trauma experienced as an adult, we created additional separate variables for early (i.e., occurred before age 16) and late (occurred at or after age 16) trauma.

BPD Screening Status. The McLean Screening Instrument for Borderline Personality Disorder (MSI-BPD) was used to establish BPD status (Zanarini et al., 2003). For the sake of brevity, we refer to patients who screened positive for BPD as the BPD group. The MSI-BPD is a 10 -item, yes or no, selfreport patient screening scale, with seven or more endorsed items resulting in a positive screen for borderline personality disorder (Zanarini et al., 2003). Items are derived from a subset of questions from the BPD module of the Diagnostic Interview for DSM-IV Personality Disorders (DIPDIV; Zanarini, Frankenburg, Sickel, \& Yong, 1996). The MSI-BPD had good sensitivity (0.81) and specificity (0.85) against a criterion diagnosis of BPD as assessed with the DIPD-IV (Zanarini et al., 2003). Subsequent calculations performed by Patel, Sharp, and Fonagy (2011) using information provided by Zanarini and colleagues (2003) revealed strong diagnostic accuracy (.83) and agreement between the MSI-BPD and DIPD-BPD (kappa $=.62)$. A more recent study found lower sensitivity (.68) and specificity (.78) of the MSI-BPD when tested against the Structured Clinical Interview for DSM-IV Axis II disorders (SCID-II) in outpatient youth (Chanen et al., 2008). However, Chanen and colleagues (2008) attributed the moderate sensitivity and specificity of the MSI to differences in the prevalence of BPD $(21.8 \%$ in the Chanen et al., 2008 study vs. $69.5 \%$ in the Zanarini et al., 2003 study) and nature of their samples (youth with acute referrals vs. adults with treatment histories) in addition to differences between the SCID-II and DIPD 
operational definitions of DSM-IV BPD criteria. Another study conducted with a heterogeneous outpatient adult sample in Germany demonstrated good psychometric properties of a German version of the MSI-BPD, which identified correctly $91 \%$ of individuals with BPD (sensitivity) and $80 \%$ of individuals without BPD (specificity) (Kroger, Vonau, Kliem, \& Kosfelder, 2010). Most recently, a study by Patel and colleagues (2011) examining the criterion validity of the MSI-BPD against the DIPD-IV in a community sample found moderate diagnostic efficiency with sensitivity and specificity values of 0.69 and 0.67 , respectively, and diagnostic accuracy of .74. The authors concluded that the MSIBPD is likely to be a valid instrument for studies on community and/or among ethnically diverse populations. As neither DIPDIV nor SCID-II was administered in the present study, no data on the validity of the MSI-BPD against a criterion diagnosis are available for our sample.

Psychiatric Comorbidity and Functional Impairment. Current psychiatric comorbidity was assessed with the Structured Clinical Interview for DSM-IV Disorders (SCID) (First, Spitzer, Gibbon, \& Williams, 1997), except for PTSD, which was assessed with the CIDI PTSD module (World Health Organization, 1997). Functional impairment was evaluated with the 10-point self-rated social life and family life/home responsibilities subscales of the Sheehan Disability Scale (SDS) (Ghafoori et al., 2009; Leon, Shear, Portera, \& Klerman, 1992), (0 = none, 1-3 = mild, 4-6 = moderate, $7-9=$ marked, $10=$ extreme). Consistent with previous studies conducted in this patient population (Ghafoori et al., 2009; Neria et al., 2006; Weissman et al., 2005), we chose a relatively conservative threshold $(\geq 7)$ for classifying significant impairment. Because only $33.3 \%$ of the 474 patients were gainfully employed (i.e., received financial compensation for work performed), the work subscale of the SDS was not used. An assessment was conducted of the num- ber of days in the past month that patients had missed school or work (paid or unpaid) or had been unable to engage in housework or regular activities. The resulting variable work loss (yes or no) was based on missing $\geq$ 7 days of these activities. Finally, two items were included from the Social Adjustment Self-Report Scale (SAS; Weissman, Prusoff, \& Thompson, 1978) to measure how well patients had gotten along with their spouse/ partner (partner relational problems) and children (child relational problems) over the past month.

All assessment forms were translated from English to Spanish and back-translated by a bilingual team of mental health professionals. Self-report assessment forms and the structured clinical interview components were completed in participants' language of choice (Spanish or English) and administered by bilingual interviewers.

\section{Data Analysis}

Individuals in the BPD and no BPD groups were classified by age (18-54 vs. 5570 ), gender, marital status (married/co-habiting vs. single/separated/divorced/widowed/ never married), level of education (graduated high school vs. did not graduate high school), household income $(<\$ 12,000$ vs. $\geq$ $\$ 12,000)$, employment status (employed vs. not employed), and having children (yes vs. no), having a partner (yes vs. no), and ethnicity (Hispanic vs. non-Hispanic). Patients were categorized as Hispanic if they identified their national origin as Latin American, were born in Spain, or chose to complete the study forms in Spanish.

We first conducted omnibus tests of bivariate associations between BPD screening status (positive vs. not positive) and various background characteristics using chi-square analyses for categorical variables and Fischer's exact test when any expected cell count was less than 5 . These variables included sociodemographic characteristics, exposure to 
TABLE 2. History of Traumatic Life Events and Borderline Personality Disorder Screening Status Among Adult Primary Care Patients $\left(n=474^{a}\right)$

\begin{tabular}{|c|c|c|c|c|c|c|c|c|}
\hline \multirow[b]{3}{*}{ Lifetime Trauma History } & \multicolumn{2}{|c|}{ Total Sample } & \multicolumn{4}{|c|}{$\begin{array}{c}\text { Borderline Personality Disorder Screen } \\
\text { Status }\end{array}$} & \multirow[b]{3}{*}{$\chi^{2}$} & \multirow[b]{3}{*}{$p$} \\
\hline & \multirow[b]{2}{*}{$n$} & \multirow[b]{2}{*}{$\%$} & \multicolumn{2}{|c|}{$\mathrm{BPD}+(n=57)$} & \multicolumn{2}{|c|}{ BPD- $(n=417)$} & & \\
\hline & & & $n$ & $\%$ & $n$ & $\%$ & & \\
\hline Natural disaster & 116 & 24.5 & 23 & 40.4 & 93 & 22.3 & 8.84 & 0.003 \\
\hline Fire or explosion & 61 & 12.9 & 15 & 26.3 & 46 & 11.1 & 10.33 & 0.001 \\
\hline Serious accident & 59 & 12.5 & 10 & 17.5 & 49 & 11.8 & 1.53 & 0.217 \\
\hline Exposure to toxic substance & 7 & 1.5 & 2 & 3.5 & 5 & 1.2 & 1.84 & 0.175 \\
\hline Physical assault & 99 & 21.1 & 22 & 40 & 77 & 18.6 & 13.43 & $<.001$ \\
\hline Assault with a weapon & 102 & 21.7 & 23 & 41.8 & 79 & 19 & 14.83 & $<.001$ \\
\hline Sexual assault & 63 & 13.4 & 20 & 35.1 & 43 & 10.4 & 26.49 & $<.001$ \\
\hline Uncomfortable sexual experience & 34 & 7.2 & 16 & 28.1 & 18 & 4.3 & 42.36 & $<.001$ \\
\hline Exposure to war zone & 12 & 2.5 & 4 & 7 & 8 & 1.9 & 5.26 & 0.022 \\
\hline Captivity & 10 & 2.1 & 5 & 8.8 & 5 & 1.2 & 13.93 & $<.001$ \\
\hline Life-threatening illness & 129 & 27.3 & 17 & 29.8 & 112 & 27 & 0.2 & 0.652 \\
\hline Life-threatening/family & 86 & 18.3 & 12 & 21.1 & 74 & 17.9 & 0.33 & 0.566 \\
\hline Sudden, violent death & 93 & 19.75 & 13 & 23.2 & 80 & 19.3 & 0.48 & 0.487 \\
\hline Sudden, unexpected death & 215 & 45.6 & 30 & 52.6 & 185 & 44.6 & 1.31 & 0.252 \\
\hline Serious injury/harm you caused & 7 & 1.5 & 4 & 7.1 & 3 & 0.7 & 13.73 & $<.001$ \\
\hline Other transportation accident & 76 & 16.2 & 12 & 21.8 & 64 & 15.4 & 1.47 & 0.226 \\
\hline Other stressful event & 55 & 12.5 & 6 & 11.1 & 49 & 12.7 & 0.11 & 0.737 \\
\hline
\end{tabular}

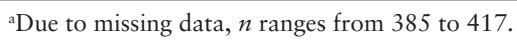

different types of traumatic events, exposure to early vs. late interpersonal and non-interpersonal trauma, Axis I psychiatric diagnoses, and functional impairment.

Next, we selected variables for inclusion in subsequent multivariate analyses based on the results of the omnibus tests. Only variables that were associated with BPD screening status at $p<.05$ were included. To investigate the relation between DSMIV Axis I psychiatric diagnoses and functional impairment and BPD screening status, we conducted a series of logistic regressions with a two-level outcome (psychiatric diagnosis vs. no psychiatric diagnosis, functional impairment vs. no functional impairment). In subsequent analyses, we adjusted for ethnicity and exposure to lifetime interpersonal trauma. All tests were two-tailed, and significance was set at $p<.05$. Statistical analyses were conducted with SPSS software version 17.0.

\section{RESULTS}

\section{Prevalence of Borderline Personality Disorder (BPD)}

The prevalence of screen-positive BPD was $12 \%$ (57/474). While patients with BPD did not differ significantly from patients without BPD on age, gender, marital status, education, annual household income, or gainful employment, they were significantly more likely to be Hispanic. Consequently, we adjusted for ethnicity in all subsequent analyses.

\section{Trauma Exposure and BPD Status}

Compared to the non-BPD group, the BPD group was more likely to have experienced interpersonal trauma such as sexual 
TABLE 3. Type and Timing of Traumatic Life Events Among Adult Primary Care Patients With and Without Borderline Personality Disorder

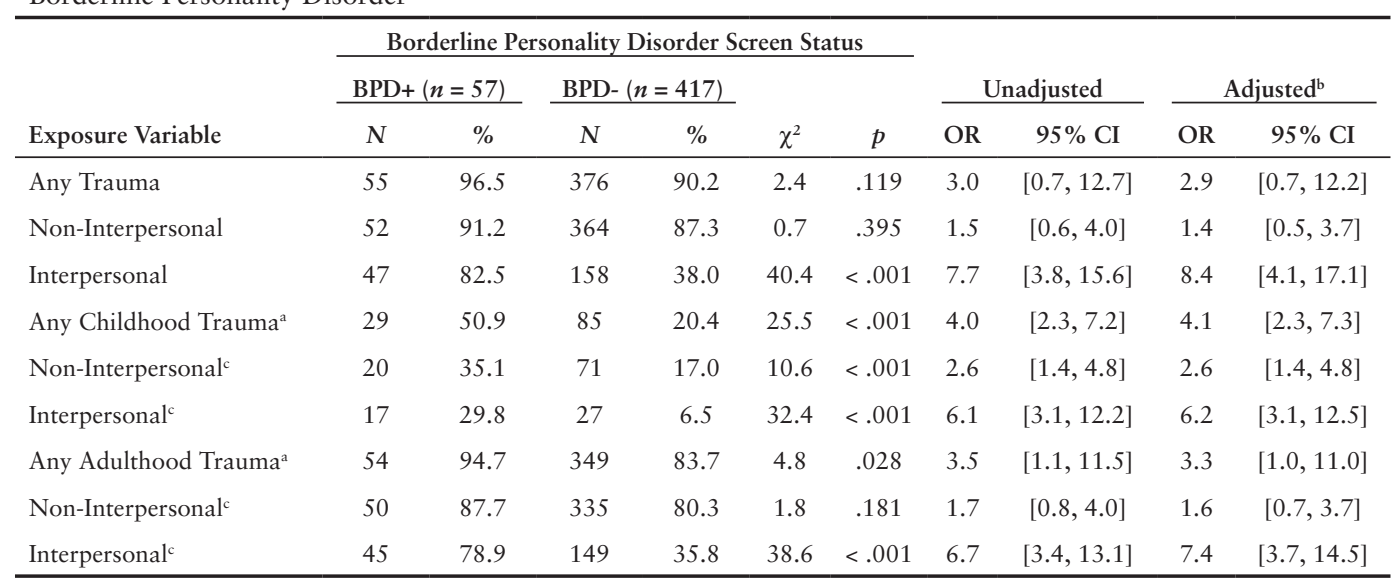

${ }^{a}$ Childhood traumatic event refers to events that occurred before age 16; adulthood traumatic event refers to events that occurred after age 16. bAdjusted for ethnicity. 'Interpersonal trauma includes physical/sexual assault or other unwanted sexual experiences and assault with a weapon; non-interpersonal trauma includes natural includes disasters, accidents, illness and/or natural death of a close person and other traumatic experiences.

and physical assault or abuse and uncomfortable sexual experiences (Table 2). The BPD group also had significantly higher rates of exposure to natural disasters, fire or explosions, and a number of rarely reported events (e.g., captivity, exposure to war zones, and having caused serious injury or harm to others. Overall, the BPD group was more likely to differ from the non-BPD group on frequently reported traumatic events with an interpersonal component compared to events without interpersonal components). Further, the BPD group was significantly more likely to have experienced interpersonal trauma in childhood $(29.8 \%$ of BPD patients reported such trauma compared to $6.5 \%$ of non-BPD patients) (Table 3). Interpersonal trauma experienced during adulthood was as strongly associated with BPD as interpersonal trauma experienced during childhood (Table 3).

Omnibus group comparisons of psychiatric diagnoses and functional status ( $\mathrm{Ta}-$ ble 4) showed that BPD screening status was significantly associated with all six DSMIV Axis I diagnoses examined in the present study. Of the 57 patients that screened positive for BPD, most $(91.2 \%)$ met crite- ria for another psychiatric diagnosis. The most commonly co-occurring disorders were PTSD $(45.6 \%)$ and major depressive disorder (MDD) (50.9\%). Compared to non-BPD patients, the BPD group had significantly higher rates of concurrent PTSD, MDD, bipolar spectrum disorder, panic disorder, generalized anxiety disorder (GAD), and alcohol or drug use disorder (Table 4).

BPD was also associated with substantial impairment in multiple areas of functioning, particularly family and social role functioning. Patients screening positive for BPD were more likely to be experiencing family and social life impairment and to report at least seven days of work loss within the past month. With the exception of child relational problems, all of the associations between BPD and functional impairment remained significant when controlling for ethnicity and lifetime history of interpersonal trauma (Table 4).

To examine to what extent DSM-IV Axis I psychiatric diagnoses accounted for functional impairment, we conducted an additional set of logistic regressions controlling for ethnicity, lifetime interpersonal trauma, and presence of any DSM-IV diagnosis (not 
TABLE 4. Psychiatric Comorbidity a and Functional Impairment Among Adult Primary Care Patients With and Without Borderline Personality Disorder

\begin{tabular}{|c|c|c|c|c|c|c|c|c|c|c|}
\hline \multirow[b]{3}{*}{ Variable } & \multicolumn{7}{|c|}{ Borderline Personality Disorder Screen Status } & \multirow{2}{*}{\multicolumn{2}{|c|}{ Unadjusted }} & \multirow{3}{*}{$\begin{array}{l}\text { Adjusted }^{\mathrm{b}} \\
95 \% \mathrm{CI}\end{array}$} \\
\hline & \multicolumn{2}{|c|}{$\mathrm{BPD}+(n=57)$} & \multicolumn{2}{|c|}{ BPD- $(n=417)$} & \multirow[b]{2}{*}{$\chi^{2}$} & \multirow[b]{2}{*}{$p$} & \multirow[b]{2}{*}{ OR } & & & \\
\hline & $N$ & $\%$ & $N$ & $\%$ & & & & $95 \%$ CI & OR & \\
\hline \multicolumn{11}{|l|}{ DSM-IV Axis I } \\
\hline Major depressive disorder & 29 & 50.9 & 103 & 24.7 & 17.1 & $<.001$ & 3.26 & {$[1.8,5.6]$} & 2.2 & {$[1.2,4.1]$} \\
\hline Panic disorder & 15 & 26.3 & 25 & 6.0 & 26.8 & $<.001$ & 5.6 & {$[2.7,11.4]$} & 6.1 & {$[2.7,13.8]$} \\
\hline Generalized anxiety disorder & 9 & 15.8 & 10 & 2.4 & 23.4 & $<.001$ & 7.6 & {$[3.0,19.7]$} & 6.1 & {$[2.1,17.6]$} \\
\hline Bipolar spectrum disorder & 22 & 38.6 & 39 & 9.4 & 38.2 & $<.001$ & 6.1 & {$[3.3,11.4]$} & 5.2 & {$[2.6,10.3]$} \\
\hline Alcohol or drug use disorder & 4 & 7.0 & 6 & 1.4 & 7.6 & .006 & 5.8 & {$[1.4,19.0]$} & 6.3 & {$[1.4,29.2]$} \\
\hline PTSD & 26 & 45.6 & 68 & 16.3 & 27.1 & $<.001$ & 4.3 & {$[2.4,7.7]$} & 3.1 & {$[1.7,5.8]$} \\
\hline Any of the above diagnoses & 52 & 91.2 & 171 & 41.0 & 50.8 & $<.001$ & 15.0 & {$[5.9,38.2]$} & 11.0 & {$[4.2,28.6]$} \\
\hline \multicolumn{11}{|l|}{ Sheenan Disability Scale } \\
\hline Family & 25 & 44.6 & 59 & 14.4 & 30.6 & $<.001$ & 4.8 & {$[2.7,8.7]$} & 3.2 & {$[1.7,6.1]$} \\
\hline Social & 30 & 52.6 & 70 & 17.2 & 37.3 & $<.001$ & 5.4 & {$[3.0,9.6]$} & 4.0 & {$[2.1,7.4]$} \\
\hline \multicolumn{11}{|l|}{ Social Adjustment Scale } \\
\hline Problems with Partner & 10 & 38.5 & 17 & 11.6 & 12.0 & $<.001$ & 4.7 & {$[1.9,12.1]$} & 2.8 & {$[1.0,7.7]$} \\
\hline Problems with Children & 8 & 15.1 & 32 & 8.4 & 2.4 & .118 & 1.9 & {$[0.8,4.4]$} & 1.2 & {$[0.5,2.8]$} \\
\hline At least 7 days of work lost & 29 & 50.9 & 95 & 24.1 & 18.0 & $<.001$ & 3.3 & {$[1.9,5.8]$} & 2.7 & {$[1.5,5.0]$} \\
\hline
\end{tabular}

shown). The only variable that remained significantly associated with BPD in these analyses was impairment in social role functioning (OR: 2.38; 95\% CI [1.25, 4.55]).

The observation that BPD was related to higher levels of trauma exposure, more Axis I comorbidity, and more functional impairment raised the question of how predictive borderline personality disorder is of functional impairment (and possible Axis I comorbidity) after controlling for PTSD, the only disorder defined in part by exposure to trauma. To address this issue, we performed additional analyses on comorbid psychiatric diagnoses and functional impairment controlling for PTSD (as measured with the PTSD module of the CIDI). Results showed that BPD remained significantly associated with all of the disorders examined as well as with measures of functional impairment except problems in child relations.

\section{DISCUSSION}

While elevated rates of sexual and physical abuse among individuals with BPD are well established, there continues to be controversy over the pathogenic role of interpersonal trauma in BPD (Paris, 2009). Using a predominantly Spanish-speaking primary care sample, the current study found that interpersonal trauma was strongly associated with BPD. Patients who reported having experienced interpersonal trauma at any point during their lives were eight times as likely to screen positive for BPD. Both childhood and adulthood interpersonally traumatic events were strongly associated with BPD while exposure to non-interpersonal trauma was associated with BPD only if it had occurred during childhood. The finding of a link between exposure to early interper- 
sonal trauma and increased risk for BPD is in line with data from both retrospective (e.g., Bandelow et al., 2005; Golier et al., 2003; Modestin et al., 2005; Sansone, Songer, \& Miller, 2005) and prospective longitudinal (Carlson, Egeland, \& Sroufe, 2009; Widom et al., 2009) studies demonstrating the significance of early adverse experiences in the development of borderline psychopathology. The present study adds to this literature by examining the relation between both early and late trauma exposure and BPD in an understudied population: low-income primary care patients who tend to be exposed to more frequent and severe trauma compared to economically advantaged majority patients. Importantly, however, our study showed that interpersonal trauma experienced during adulthood was as strongly associated with screening positive for BPD as interpersonal trauma experienced during childhood in this ethnic minority, primarily female sample of primary care patients.

One reason for this finding might be the disturbing and violent nature of interpersonal trauma that might lead to long-term adverse psychological consequences regardless of when it occurred. Exposure to severe interpersonal trauma in childhood has been associated with a range of social impairments in adulthood, such as problems with intimate partner relations, disturbed sexual functioning, parenting difficulties, and social withdrawal (DiLillo, 2001). Interpersonal trauma may have cumulative effects on social functioning that undermine recovery from later trauma. Thus, survivors of childhood sexual abuse often struggle to manage interpersonal conflict and to experience interactions with other people as rewarding (Cloitre, Koenen, Cohen, \& Han, 2002; Cloitre, Scarvalone, \& Difede, 1997). These social dysfunctions may in turn detract from their ability to maintain existing and build new social support systems after subsequent trauma or in the face of repeated and continuing trauma such as domestic violence. While in- dividuals who develop PTSD in response to CSA also often exhibit social impairments, individuals with BPD are particularly vulnerable to re-victimization given their tendency to engage in risky and impulsive behaviors such as substance abuse and their greater likelihood to be in volatile and abusive relationships (American Psychiatric Association, 2000; Paris, 2005). This vulnerability is likely to be magnified in individuals with comorbid PTSD and BPD, perhaps owing to increased emotion dysregulation (MarshallBerenz, Morrison, Schumacher, \& Coffey, 2011). Findings from the present study suggested that BPD contributed above and beyond PTSD to problems in social and family role functioning as well as in partner relationships. The only variable that appeared to be more affected by PTSD than by BPD in this sample was child relational problems. It is possible that some aspects of PTSD, such as emotional numbing and withdrawal, may detract from the ability to relate to one's children more than core borderline traits such as impulsivity, which tends to disrupt the maintenance of intimate relationships and has been found to prospectively predict social maladjustment above and beyond Axis I psychopathology (Bagge et al., 2004). In Selby and Joiner's (2008) factor-analytic study of ethnic variations in the structure of $\mathrm{BPD}$, impulsivity loaded onto the disturbed relatedness factor in BPD among Hispanics, but not Caucasians, Asians, or other ethnic groups examined in this study. Interestingly, the disturbed relatedness factor showed the least congruence in Caucasian and Hispanic group comparisons. Given the centrality of family in Hispanic culture, examining dysfunctions in child-parent relations among individuals with comorbid PTSD and BPD merits further investigation and might be an important target of intervention.

The high levels of psychiatric comorbidity found in BPD patients in the present study is consistent with observations that $\mathrm{BPD}$, as compared to other personality dis- 
orders, is particularly likely to co-occur with mood, anxiety, substance use, eating, and somatoform disorders (Tadic et al., 2009; Zanarini et al., 1998; Zimmerman \& Mattia, 1999). The extremely high proportion of the BPD group with comorbid diagnoses in our sample $(91 \%)$ has clinical implications. First, it highlights the importance of increasing awareness among primary care health professionals of the mental health needs of individuals presenting with behavioral characteristics of BPD. Second, the results highlight the potential use of the BPD screening scale as a short and easily administered measure in primary care settings. Given that individuals screening positive for BPD were found to suffer from a variety of psychiatric diagnoses, administering the MSI-BPD might be a useful first step for identifying individuals in need of more extensive mental health assessment (including structured clinical interviews) and referral.

The study has several limitations. First, a cross-sectional design relying on a single time point to explore the relation between interpersonal trauma and BPD poses problems of temporal sequencing of exposures, disorder onset, and impairment. Second, no structured clinical interview for personality disorders was administered in the present study that could have been used to examine the criterion validity of the MSIBPD. Future research is needed to obtain information on diagnostic agreement between the Spanish version of the MSI-BPD utilized in the present study and validated structured clinical interviews such as the SCID-II or DIPD-IV. Third, because the survey had a relatively low response rate at Wave 2 , a potential for selection bias exists. For example, rates of BPD and functional impairment in our sample may have been inflated by overrepresentation of more impaired patients with limited access to specialty mental health clinics seeking help in primary care clinics. A related weakness is that our sample was relatively restricted in consisting primarily of low-income, Hispanic primary care patients.
It would have been desirable to have a more heterogeneous sample to conduct targeted comparisons between Hispanic and non-Hispanic patients. Fourth, we used self-report to assess trauma exposure, which is known to be subject to bias, especially in emotionally vulnerable individuals (White, Widom, \& Chen, 2007; Widom et al., 2009; Widom, Raphael, \& DuMont, 2004). However, data from The Adverse Childhood Experiences (ACE) Study, a large epidemiological study that examined health and social consequences of exposure to a range of childhood stressors in primary care patients using a survey incorporating questions from different selfreport measures, suggest that test-retest reliability at two time points may be acceptable for retrospective recall of adverse childhood experiences (Dube, Williamson, Thompson, Felitti, \& Anda, 2004).

A methodological strength of the present study is that it used an empirically validated screening instrument with a comparatively large primary care sample. Of the limited number of studies that assess BPD in the primary care setting, most have methodological limitations including small sample size (Gross et al., 2002; Hueston, Mainous, \& Schilling, 1996; Sansone et al., 2001; Sansone, Wiederman, \& Sansone, 1998) and unreliable or overly sensitive diagnostic instruments (Hueston et al., 1996; Sansone et al., 2001; Sansone et al., 1998).

The present study adds to the literature on BPD in primary care by focusing on an understudied population facing elevated risk for a range of traumatic experiences including severe interpersonal trauma (Nnamdi et al., 2008). Given the growing percentage of Hispanics among the total U.S. population (Suro, 2005), there is a need for an increased understanding of factors that might increase vulnerability to chronic and debilitating psychiatric disorders including BPD among Hispanic patients attending general medical practices. A strong association exists between lifetime interpersonal trauma and $\mathrm{BPD}$, drawing attention to the impor- 
tance of screening for BPD in primary care patients who report having experienced interpersonal trauma. Increased awareness of the prevalence of BPD among minorities receiving primary care and the high rates of trauma exposure in this population may enhance physicians' ability to detect and provide appropriate referrals for BPD patients.

\section{REFERENCES}

American Psychiatric Association. (2000). Diagnostic and statistical manual of mental disorders (4th ed., text rev.). Washington, DC: Author.

Bagge, C., Nickell, A., Stepp, S., Durrett, C., Jackson, K., \& Trull, T. J. (2004). Borderline personality disorder features predict negative outcomes 2 years later. Journal of Abnormal Psychology, 113(2), 279-288. doi:10.1037/0021843x.113.2.279

Bandelow, B., Krause, J., Wedekind, D., Broocks, A., Hajak, G., \& Ruther, E. (2005). Early traumatic life events, parental attitudes, family history, and birth risk factors in patients with borderline personality disorder and healthy controls. Psychiatry Research, 134(2), 169-179. doi:10.1016/j. psychres.2003.07.008

Battle, C. L., Shea, M. T., Johnson, D. M., Yen, S., Zlotnick, C., Zanarini, M. C., . . . Morey, L. C. (2004). Childhood maltreatment associated with adult personality disorders: Findings from the collaborative longitudinal personality disorders study. Journal of Personality Disorders, 18(2), 193-211.

Bornovalova, M. A., Hicks, B. M., Iacono, W. G., \& McGue, M. (2009). Stability, change, and heritability of borderline personality disorder traits from adolescence to adulthood: A longitudinal twin study. Development and Psychopathology, 21(4), 1335-1353. doi:10.1017/ s0954579409990186

Breslau, N., Kessler, R. C., Chilcoat, H. D., Schultz, L. R., Davis, G. C., \& Andreski, P. (1998). Trauma and posttraumatic stress disorder in the community: The 1996 Detroit Area Survey of Trauma. Archives of General Psychiatry, 55, 626632.

Bryant-Davis, T., Chung, H., \& Tillman, S. (2009). From the margins to the center. Trauma, Violence, \& Abuse, 10(4), 330.

Carlson, E. A., Egeland, B., \& Sroufe, L. A. (2009). A prospective investigation of the de- velopment of borderline personality symptoms. Development and Psychopathology, 21(4), 13111334. doi:10.1017/s0954579409990174

Castaneda, R., \& Franco, H. (1985). Sex and ethnic distribution of borderline personality disorder in an inpatient sample. American Journal of Psychiatry, 142(10), 1202-1203.

Chanen, A. M., Jovev, M., Djaja, D., McDougall, E., Yuen, H. P., Rawlings, D., \& Jackson, H. J. (2008). Screening for borderline personality disorder in outpatient youth. Journal of Personality Disorders, 22(4), 353-364.

Chavira, D. A., Grilo, C. M., Shea, M. T., Yen, S., Gunderson, J. G., Morey, L. C., .. . McGlashan, T. H. (2003). Ethnicity and four personality disorders. Comprehensive Psychiatry, 44(6), 483-491. doi:10.1016/s0010-440x(03)00104-4

Cloitre, M., Koenen, K. C., Cohen, L. R., \& Han, H. (2002). Skills training in affective and interpersonal regulation followed by exposure: A phasebased treatment for PTSD related to childhood abuse. Journal of Consulting and Clinical Psychology, 70(5), 1067-1074. doi:10.1037/0022006x.70.5.1067

Cloitre, M., Scarvalone, P., \& Difede, J. (1997). Posttraumatic stress disorder, self- and interpersonal dysfunction among sexually retraumatized women. Journal of Traumatic Stress, 10(3), 437452.

Crowell, S. E., Beauchaine, T. P., \& Linehan, M. M. (2009). A biosocial developmental model of borderline personality: Elaborating and extending linehan's theory. Psychological Bulletin, 135(3), 495-510. doi:10.1037/a0015616

DiLillo, D. (2001). Interpersonal functioning among women reporting a history of childhood sexual abuse: Empirical findings and methodological issues. Clinical Psychology Review, 21(4), 553-576. doi:10.1016/S0272-7358(99)00072-0

Dube, S. R., Williamson, D. F., Thompson, T., Felitti, V. J., \& Anda, R. F. (2004). Assessing 
the reliability of retrospective reports of adverse childhood experiences among adult HMO members attending a primary care clinic. Child Abuse \& Neglect, 28(7), 729-737. doi:10.1016/j.chiabu.2003.08.009

First, M. B., Spitzer, R. L., Gibbon, M., \& Williams, J. B. W. (1997). Structured clinical interview for DSM-IV axis I disorders. Washington, DC: American Psychiatric Press.

Fossati, A., Madeddu, F., \& Maffei, C. (1999). Borderline personality disorder and childhood sexual abuse: A meta-analytic study. Journal of Personality Disorders, 13(3), 268-280. doi:10.1521/pedi.1999.13.3.268

Ghafoori, B., Neria, Y., Gameroff, M., Olfson, M., Lantigua, R., \& Shea, S. (2009). Screening for generalized anxiety disorder symptoms in the wake of terrorist attacks: A study in primary care. Journal of Traumatic Stress, 22, 212-226.

Golier, J. A., Yehuda, R., Bierer, L. M., Mitropoulou, V., New, A. S., Schmeidler, J., . . . Siever, L. J. (2003). The relationship of borderline personality disorder to posttraumatic stress disorder and traumatic events. American Journal of Psychiatry, 160(11), 2018-2024.

Grant, B. F., Chou, S. P., Goldstein, R. B., Huang, B., Stinson, F. S., Saha, T. D., . . . Ruan, W. J. (2008). Prevalence, correlates, disability, and comorbidity of DSM-IV borderline personality disorder: Results from the Wave 2 National Epidemiologic Survey on Alcohol and Related Conditions. Journal of Clinical Psychiatry, 69(4), 533-545.

Gray, M. J., Litz, B. T., Hsu, J. L., \& Lombardo, T. W. (2004). Psychometric properties of the life events checklist. Assessment, 11, 330-341.

Gresenz, C. R., Sturm, R., \& Tang, L. (2001). Income and mental health: Unraveling community and individual level relationships. Journal of Mental Health Policy and Economics, 4(4), 197204.

Grilo, C. M., Becker, D. F., Anez, L. M., \& McGlashan, T. H. (2004). Diagnostic efficiency of DSM-IV criteria for borderline personality disorder: An evaluation in Hispanic men and women with substance use disorders. Journal of Consulting and Clinical Psychology, 72(1), 126-131. doi:10.1037/0022-006x.72.1.126
Grilo, C. M., McGlashan, T. H., Morey, L. C., Gunderson, J. G., Skodol, A. E., Shea, M. T., ... Stout, R. L. (2001). Internal consistency, intercriterion overlap and diagnostic efficiency of criteria sets for DSM-IV schizotypal, borderline, avoidant and obsessive-compulsive personality disorders. Acta Psychiatrica Scandinavica, 104(4), 264-272. doi:10.1034/j.1600-0447.2001.00436.x

Gross, R., Olfson, M., Gameroff, M., Shea, S., Feder, A., Fuentes, M., . . . Weissman, M. M. (2002). Borderline personality disorder in primary care. Archives of Internal Medicine, 162, 53-60.

Gunderson, J. G., Daversa, M. T., Grilo, C. M., McGlashan, T. H., Zanarini, M. C., Shea, M. T., . . Stout, R. L. (2006). Predictors of 2-year outcome for patients with borderline personality disorder. American Journal of Psychiatry, 163(5), 822-826.

Hueston, W. J., Mainous, A. G., \& Schilling, R. (1996). Patients with personality disorders: Functional status, health care utilization, and satisfaction with care. Journal of Family Practice, 42(1), 54-60.

Hueston, W. J., Werth, J., \& Mainous, A. G. (1999). Personality disorder traits: Prevalence and effects on health status in primary care patients. International Journal of Psychiatry in Medicine, 29(1), 63-74.

Kessler, R. C., Sonnega, A., Bromet, E., Hughes, M., \& Nelson, C. B. (1995). Posttraumatic stress disorder in the national comorbidity survey. Archives of General Psychiatry, 52, 1048-1060.

Korfine, L., \& Hooley, J. M. (2009). Detecting individuals with Borderline Personality Disorder in the community: An ascertainment and comparison with a hospital sample. Journal of Personality Disorders, 23(1), 62-75.

Korzekwa, M. I., Dell, P. F., Links, P. S., Thabane, L., \& Webb, S. P. (2008). Estimating the prevalence of borderline personality disorder in psychiatric outpatients using a two-phase procedure. Comprehensive Psychiatry, 49(4), 380-386. doi:10.1016/j.comppsych.2008.01.007

Kroger, C., Vonau, M., Kliem, S., \& Kosfelder, J. (2010). Screening measure for borderline personality disorder. Psychotherapie Psychosomatik Medizinische Psychologie, 60(9-10), 391-396. doi:10.1055/s-0030-1248279 
Kulka, R. A., Schlenger, W. E., Fairbank, J. A., Hough, R. L., Jordan, B. K., Marmar, C. R., \& Weiss, D. S. (1990). Trauma and the Vietnam war generation: Report of findings from the National Vietnam Veterans Readjustment Study. Philadelphia: Brunner/Mazel.

Leon, A. C., Shear, M. K., Portera, L., \& Klerman, G. L. (1992). Assessing impairment in patients with panic disorder: The Sheehan Disability Scale. Social Psychiatry and Psychiatric Epidemiology, 27, 78-82.

Lubit, R., Rovine, D., DeFrancisci, L., \& Eth, S. (2003). Impact of trauma on children. Journal of Psychiatric Practice, 9(2), 128-138.

Marshall-Berenz, E. C., Morrison, J. A., Schumacher, J. A., \& Coffey, S. F. (2011). Affect intensity and lability: The role of posttraumatic stress disorder symptoms in borderline personality disorder. Depression and Anxiety, 28(5), 393-399. doi:10.1002/da.20798

Modestin, J., Furrer, R., \& Malti, T. (2005). Different traumatic experiences are associated with different pathologies. Psychiatric Quarterly, 76(1), 19-32. doi:10.1007/s11089-005-5578-y

Neria, Y., Gross, R., Olfson, M., Gameroff, M. J., Wickramaratne, P., Das, A., .. . Weissman, M. M. (2006). Posttraumatic stress disorder in primary care one year after the 9/11 attacks. General Hospital Psychiatry, 28, 213-222. doi:10.1016/j. genhosppsych.2006.02.002

Neria, Y., Olfson, M., Gameroff, M. J., Wickramaratne, P., Gross, R., Pilowsky, D. J., . . . Weissman, M. M. (2008). The mental health consequences of disaster-related loss: Findings from primary care one year after the 9/11 terrorist attacks. Psychiatry, 71(4), 339-348. doi:10.1521/ psyc.2008.71.4.339

Neria, Y., Olfson, M., Gameroff, M. J., DiGrande, L., Wickramaratne, P., Gross, R., . . . Weissman, M. M. (2010). Long-term course of probable PTSD after the 9/11 attacks: A study in urban primary care. Journal of Traumatic Stress, 23(4), 474-482. doi:10.1002/jts.20544

Neria, Y., Wickramaratne, P., Olfson, M., Gameroff, M. J., Pilowsky, D. J., Lantigua, R., ... Weissman, M. M. (2013). Mental and physical health consequences of the September 11, 2001 (9/11) attacks in primary care: A longitudinal study. Journal of Traumatic Stress, 26(1), 45-55. doi:10.1002/jts.21767

Nnamdi, P., Joseph, P. G., \& Madhur, K. (2008). Posttraumatic stress disorder among ethnoracial minorities in the United States. Clinical Psychology, 15(1), 35-61.

Ogata, S. N., Silk, K. R., Goodrich, S., Lohr, N. E., Westen, D., \& Hill, E. M. (1990). Childhood sexual and physical abuse in adult patients with borderline personality disorder. American Journal of Psychiatry, 147(8), 1008.

Olfson, M., Broadhead, W. E., Weissman, M. M., Leon, A. C., Farber, L., Hoven, C., \& Kathol, R. (1996). Subthreshold psychiatric symptoms in a primary care group practice. Archives of General Psychiatry, 53(10), 880-886.

Paris, J. (2005). Borderline personality disorder. Canadian Medical Association Journal, 172(12), 1579-1583. doi:10.1503/cmaj.045281

Paris, J. (2009). The treatment of borderline personality disorder: Implications of research on diagnosis, etiology, and outcome. Annual Review of Clinical Psychology, 5(1), 277-290. doi:10.1146/ annurev.clinpsy.032408.153457

Pascual, J. C., Malagon, A., Corcoles, D., Gines, J. M., Soler, J., Garcia-Ribera, C., . . . Bulbena, A. (2008). Immigrants and borderline personality disorder at a psychiatric emergency service. British Journal of Psychiatry, 193(6), 471-476. doi:10.1192/bjp.bp.107.038208

Patel, A., Sharp, C., \& Fonagy, P. (2011). Criterion validity of the MSI-BPD in a community sample of women. Journal of Psychopathology and Behavioral Assessment, 33(3), 403-408. doi:10.1007/s10862-011-9238-5

Perilla, J., Norris, F., \& Lavizzo, E. (2002). Ethnicity, culture, and disaster response: Identifying and explaining ethnic differences in PTSD six months after Hurricane Andrew. Journal of Social and Clinical Psychology, 21(1), 20-45.

Samuels, J., Eaton, W. W., Bienvenu, O. J., Brown, C. H., Costa, P. T., \& Nestadt, G. (2002). Prevalence and correlates of personality disorders in a community sample. British Journal of Psychiatry, 180, 536-542.

Sansone, R. A., \& Sansone, L. A. (2003). Borderline personality: Different symptoms in different treatment settings? International Journal 
of Psychiatry in Clinical Practice, 7(3), 187-191. doi:10.1080/13651500310000898

Sansone, R. A., Songer, D. A., \& Miller, K. A. (2005). Childhood abuse, mental healthcare utilization, self-harm behavior, and multiple psychiatric diagnoses among inpatients with and without a borderline diagnosis. Comprehensive Psychiatry, 46(2), 117-120. doi:10.1016/j.comppsych.2004.07.033

Sansone, R. A., Whitecar, P., Meier, B. P., \& Murry, A. (2001). The prevalence of borderline personality among primary care patients with chronic pain. General Hospital Psychiatry, 23(4), 193-197.

Sansone, R. A., Wiederman, M. W., \& Sansone, L. A. (1998). Borderline personality symptomatology, experience of multiple types of trauma, and health care utilization among women in a primary care setting. Journal of Clinical Psychiatry, 59(3), 108-111.

Selby, E. A., \& Joiner Jr., T. E. (2008). Ethnic variations in the structure of borderline personality disorder symptomatology. Journal of Psychiatric Research, 43(2), 115-123. doi:10.1016/j.jpsychires.2008.03.005

Suro, R. (2005). Hispanics: A people in motion. Washington, DC: Pew Hispanic Center.

Tadic, A., Wagner, S., Hoch, J., Baskaya, O., von Cube, R., Skaletz, C., . . . Dahmen, N. (2009). Gender differences in axis I and axis II comorbidity in patients with borderline personality disorder. Psychopathology, 42(4), 257-263. doi:10.1159/000224149

Torgersen, S., Kringlen, E., \& Cramer, V. (2001). The prevalence of personality disorders in a community sample. Archives of General Psychiatry, 58(6), 590-596.

Van den Bosch, L. M. C., Verheul, R., Langeland, W., \& Van den Brink, W. (2003). Trauma, dissociation, and posttraumatic stress disorder in female borderline patients with and without substance abuse problems. Australian and New Zealand Journal of Psychiatry, 37(5), 549-555.

Weissman, M. M., Neria, Y., Das, A., Feder, A., Blanco, C., Lantiqua, R., ...Olfson, M. (2005). Gender differences in posttraumatic stress disorder among primary care patients after the World
Trade Center attack of September 11, 2001. Gender Medicine, 2, 76-87.

Weissman, M. M., Neria, Y., Gameroff, M. J., Pilowsky, D. J., Wickramaratne, P., \& Lantigua, R. (2010). Positive screens for psychiatric disorders in primary care: A long-term follow-up of patients who were not in treatment. Psychiatric Services, 61, 151-159.

Weissman, M. M., Prusoff, B. A., \& Thompson, W. D. (1978). Social adjustment by self-report in a community sample and in psychiatric outpatients. Journal of Nervous and Mental Disease, 166, 317-326.

White, H. R., Widom, C. S., \& Chen, P. H. (2007). Congruence between adolescents' self-reports and their adult retrospective reports regarding parental discipline practices during their adolescence. Psychological Reports, 101(3), 1079-1094. doi:10.2466/pr0.101.4.1079-1094

Widiger, T. A., \& Weissman, M. M. (1991). Epidemiology of borderline personality disorder. Hospital and Community Psychiatry, 42(10), 1015-1021.

Widom, C. S., Czaja, S. J., \& Paris, J. (2009). A prospective investigation of borderline personality disorder in abused and neglected children followed up into adulthood. Journal of Personality Disorders, 23(5), 433-446.

Widom, C. S., Raphael, K. G., \& DuMont, K. A. (2004). The case for prospective longitudinal studies in child maltreatment research: Commentary on Dube, Williamson, Thompson, Felitti, and Anda (2004). Child Abuse \& Neglect, 28(7), 715722. doi:10.1016/j.chiabu.2004.03.009

World Health Organization. (1997). Composite International Diagnostic Interview (CIDI): Version 2.1. Geneva, Switzerland: Author.

Yen, S., Shea, M. T., Battle, C. L., Johnson, D. M., Zlotnick, C., Dolan-Sewell, R., ... McGlashan, T. H. (2002). Traumatic exposure and posttraumatic stress disorder in borderline, schizotypal, avoidant, and obsessive-compulsive personality disorders: Findings from the collaborative longitudinal personality disorders study. Journal of Nervous and Mental Disease, 190(8), 510-518. doi:10.1097/01.nmd.0000026620.66764.78

Zanarini, M., Frankenburg, F., Sickel, A., \& Yong, L. (1996). The diagnostic interview for 
DSM-IV personality disorders. Belmont, MA: McLean Hospital, Laboratory for the Study of Adult Development.

Zanarini, M. C. (2000). Childhood experiences associated with the development of borderline personality disorder. Psychiatric Clinics of North America, 23(1), 89-101.

Zanarini, M. C., Frankenburg, F. R., Dubo, E. D., Sickel, A. E., Trikha, A., Levin, A., \& Reynolds, V. (1998). Axis I comorbidity of borderline personality disorder. American Journal of Psychiatry, 155(12), 1733-1739.

Zanarini, M. C., Frankenburg, F. R., Hennen, J., Reich, D. B., \& Silk, K. R. (2005). Psychosocial functioning of borderline patients and axis II comparison subjects followed prospectively for six years. Journal of Personality Disorders, 19(1), 19-29.

Zanarini, M. C., Vujanovic, A. A., Parachini, E. A., Boulanger, J. L., Frankenburg, F. R., \& Hennen, J. (2003). A screening measure for BPD: The McLean Screening Instrument for Borderline Per- sonality Disorder (MSI-BPD). Journal of Personality Disorders, 17(6), 568-573.

Zanarini, M. C., Williams, A. A., Lewis, R. E., Reich, R. B., Vera, S. C., Marino, M. F., . . Frankenburg, F. R. (1997). Reported pathological childhood experiences associated with the development of borderline personality disorder. American Journal of Psychiatry, 154(8), 1101.

Zimmerman, M., \& Mattia, J. I. (1999). Axis I diagnostic comorbidity and borderline personality disorder. Comprehensive Psychiatry, 40(4), 245-252.

Zlotnick, C., Johnson, D. M., Yen, S., Battle, C. L., Sanislow, C. A., Skodol, A. E., . . . Shea, M. T. (2003). Clinical features and impairment in women with borderline personality disorder (BPD) with posttraumatic stress disorder (PTSD), BPD without PTSD, and other personality disorders with PTSD. Journal of Nervous and Mental Disease, 191(11), 706-713. doi:10.1097/01. nmd.0000095122.29476.ff 
Reproduced with permission of the copyright owner. Further reproduction prohibited without permission. 